\title{
Methodological Aspects of Evaluation of Digitalization of Lean Production Tools
}

\author{
Natalya Soldatova \\ Institute of marketing \\ The State University of Management \\ Moscow, Russia \\ pankratova_n_f@mail.ru
}

\author{
Svetlana Ilyashenko \\ Department of trade policy \\ Plekhanov Russian University of \\ Economics \\ Moscow, Russia \\ ilyashenko.sb@rea.ru
}

\author{
Ilya Soloviev \\ Graduate student of FGBEU the \\ National research University "MPEI» \\ Moscow, Russia
}

\begin{abstract}
Until recently, it was enough for industrial enterprises to buy the best available technology and use it more efficiently than competitors. Lean manufacturing was the most reliable tool to achieve the goal of forming a strategic economic portfolio. This paradigm ends today. Lean manufacturing by its philosophy forms a competitive advantage for the enterprise that has implemented Lean-tools in production processes. In this aspect, digitalization offers another way to increase productivity. Future competitiveness will be highest for those companies that plan to integrate lean manufacturing with digital technologies.

Investments in digital technologies have become important, but the effectiveness of the transformation will depend not on special sensors, algorithms, models or Analytics tools, but on the effectiveness of the integration of Lean-tools with modern information technologies of production management. Production processes of companies operating in the nuclear power industry are not typical, which does not contribute to the effective implementation of packaged information products. The modern market of IT solutions is represented by a sufficient number of software products, but the specifics of the energy sector makes special demands on the digitization of management processes.

In the near future, nuclear power companies will need to establish effective interaction and cooperation both within the company and with external partners, which is impossible without digital support for management decisions.
\end{abstract} sector

Keywords: lean manufacturing, lean production, energy

\section{INTRODUCTION}

Russian industrial companies are forced to operate in conditions of economic uncertainty and while market indicators indicate a record slowdown in the global economy, the global imbalance of the economic system, domestic industrial enterprises should focus on the processes of optimization of losses and processes of value creation.

In order to maintain stability in its development, the Russian industrial enterprise has to carry out serious transformations; one of the strategic directions is the digitalization of production and management processes. The digital transformation of an industrial enterprise involves a global change in both business processes and business models-in order to formalize and optimize the production activities of the enterprise, generate the optimal amount of profit and create value for customers. Modern digital business models are focused on obtaining additional revenue from digital solutions, improving the efficiency of communications with the external environment.
The concept of lean manufacturing (LP) is not a set of cost optimization tools that can be used separately from each other. In the practice of using the concept of lean production, companies often focus on individual aspects of the process, instead of focusing on the process as a whole. Thus, the LP concept acts as a group of solutions that must be applied simultaneously: improvement of the production process in order to optimize costs (SMED-Single-Minute Exchange of Dies - when part of the process is a sub-process of research and development; Just-in-time; Kanban [3]; SOP-standard operating procedure; TPM-Total Productive Maintenance; $5 S$ - a system of organization and rationalization of the workspace, consisting of five consecutive steps: sorting, maintaining order, keeping clean, standardization, improvement; VSM-Value Stream Mapping-value stream map); continuous improvement of quality (Kaizen, Jidoka); training and motivation of personnel (Kaizen, 5S); creation of a "pulling system" from the end user of products (Just-intime, Kanban, VSM).

\section{LiterAture REVIEW AND RESEARCH METHODS}

Such studies as $[1,2,4]$ are devoted to the development of the concept of lean production to improve the efficiency of its implementation in manufacturing companies in developing countries.

Bhamu J, Sangwan KS in their study [5] conduct a detailed review of scientific sources on the problems of LP implementation.

The impact of LP technologies on process automation in the industry 4.0 concept. it is considered in works $[6,7,8]$.

The requirements for the methodology of evaluation and selection of digitization technologies for lean production systems are given in $[9,10]$

The stability of the production company is the most important element in ensuring its competitiveness, which according to some authors $[11,12,13]$ is based on the introduction of a multi-stage ERP system.

The sustainability of a manufacturing company is a crucial element in its development process and for providing the company with a competitive advantage. Company managers should asses all three sustainable dimensions in order to determine the processes or actions needed to be carried out within a company with the aim of increasing the company's sustainability [14]. 
This study was conducted among the leaders of the use of Lean production in the Russian nuclear industry. The task was to compare the best practices of implementation, application of BP concepts in the integration of Lean-tools with modern information technologies of production management, such as ERP, APS, MES, etc.and to find a correlation between them. It was revealed that $77 \%$ of companies use MES-systems in their Continuous improvement programs conducted by Lean and Six Sigma methods.

Increasing automation of manufacturing has changed the relationship between workers and the technology employed to get work done. Cognitive work is replacing manual labour. Established productivity improvement methods need to comprehend increased complexity, less tractable processes and a workforce where expertise is a differentiator of outcomes [15].

Digital technologies open up opportunities for the growth of the company's productivity in General, and labor productivity in particular. Despite a number of negative trends both in the world economy and in the domestic economy, most Russian leaders develop the practice of constantly improving the culture of production. Without the concept and ideology of lean production, such as-customer orientation, building continuous production flows, workplace organization (5S), and problem solving skills (PDCA, DMAIC) - the project to integrate LP tools with modern digital technologies is doomed to low results.

The joint study analyzed the activities of leading companies in the Russian nuclear industry, which have introduced a number of digital technologies and recorded a significant increase in a number of performance indicators. Based on the results of the study, the authors formulated 4 main conclusions regarding the experience gained and forecasts from the concept of Lean production 4.0. Based on the results of the study and our experience of cooperation with a number of NGOs working in the nuclear industry, we have developed a methodological approach to assessing the effectiveness of digital integration of Lean production tools.

\section{RESULTS}

Half of the companies in our study have dedicated data Analytics services: at the corporate level to centralize competencies or at the business unit level to maintain close interaction with operational units. However, $38 \%$ of the companies surveyed currently employ individual workers on one-off assignments in data Analytics; another $9 \%$ have no data Analytics professionals at all.

Russian companies operating in the B2B market in General, and in particular, focused on the needs of the nuclear industry, faced increased competition between enterprises, including public and private companies. As a consequence of this competition, there is an increase in the requirements of nuclear industry enterprises to manufacture a batch of products to order. This trend induces the development of micro markets, and as a consequence, there is a decrease in the size of the series of the produced batch, which contributes to an increase in the variety of products (from large-scale to small-scale production). These factors affecting scientific and production processes dictate the need to develop and apply a system of indicators to assess the integration of digital technologies with lean production tools.
The previous stage of the evolution of the concept of lean production, based on the analog implementation of its principles, methods and tools, faced with the changed conditions of market relations, the limited use of BP in the fourth industrial revolution. Synchronization and standardization of various processes (from research to management) does not provide the expected effect for the production of individual series.

Digitalization technologies are based on the total application of information and communication technologies (ICT) with a focus on optimizing information flows at added value to products.

Active application of $4 \mathrm{G}$ technology by nuclear industry enterprises (within Industrie 4.0) allows enterprises to influence all processes and key performance indicators of BP instruments. This can be achieved by increasing the adaptive flexibility and speed of response through the transmission of digital information, which will ensure the growth of the effect in the scientific and production process despite the expansion of the product line while reducing the time of orders.

Integration of digital technologies with lean production tools improves the management of cross-functional groups of NGO employees, connecting the cross-functional group (as the object of management) with the company's resources allocated for a specific project.

Digitalization technologies in terms of analysis of large data sets and advanced algorithms can help to overcome the limitations within the BP by mobilizing further potential for lean production and purposeful improvement of the integration of tools by enterprises in the nuclear industry.

Lean production tools and a sufficient level of application of lean production systems in Russian companies are factors contributing to the introduction of digitalization tools, which is much more effective than focusing on improving the processes of value creation and waste optimization. Choosing the right digitalization technologies for NGOs is difficult, as knowledge and practice about the benefits of implemented technologies is not yet sufficient.

\section{DISCUSSION}

In this study, the authors examined several models for integrating BP tools and related digital technologies. In particular, a model based on the digital compatibility of information and communication technologies, multi-level interaction with partners supporting end-to-end processes along the horizontal value chain.

Multilevel interaction between market participants involves measuring and building a correlation between indicators: lead time, product quality, logistics reliability, productivity, flexibility in adapting to market conditions.

In addition to identifying the correlation between BP tools and digital technologies, a model was studied to determine the strategy for implementing lean methods. This model evaluates the impact of lean methods and tools and supports the identification of a suitable chronology of how to implement lean methods with respect to emerging effects. This approach to the evaluation of effects and applied digital technologies is based on the application of integrated Monte Carlo simulation. 
There are approaches to choosing digital technologies for the production environment at different levels. This methodology in the field of production management focuses on the selection of the optimal production technology. Further approaches to choosing the appropriate digitalization technology have an encapsulated strategy. One approach relies on technologies such as flow or pull.

Another is the possibility of selection by maturity level of digitalization technologies and limit the application at the level of a particular shop. The choice of the appropriate digitalization technology is determined by the specificity of production processes; for a company, a lean production system is often very difficult to implement due to lack of knowledge about the consequences of potential implementation.

Systems for display of interdependence of elements of $\mathrm{BP}$ and technology of digitalization are not formed. In addition, the assessment of the impact of digitalization technologies on BP tools does not sufficiently take into account digitalization technologies in terms of value creation or waste optimization. Thus, since the procedures for choosing digitalization technologies are largely encapsulated, they will not be applied in practice.

Summarizing the state of research, we can say that there is no methodology for a comprehensive assessment of the tools of BP digitization technology.

\section{CONCLUSION}

Conclusion 1. Japanese and German companies have gone the furthest in digitalizing domestic operations. They have developed digital interoperability that supports end-toend processes with horizontal value chain partners. By investing heavily in technology and staff training, they view digital transformation primarily in terms of improving operational efficiency, reducing costs, and quality control.

Conclusion 2. Experience with companies from the United States shows that U.S. companies plan to allocate more funds for the development of revolutionary business models, as companies are actively engaged in the digitalization of their products and services.

Conclusion 3. Chinese industrial enterprises stand out on all aspects of digitalization: by 2020, they expect to reduce costs and increase revenues from digital solutions. China is one of those countries that can get the maximum benefit from automation and digitalization of production processes as a solution in response to the growing remuneration of employees with a high share of labor in the production process. In addition, Chinese companies demonstrate high flexibility and openness to digital change.

\section{REFERENCES}

[1] G. Yadav, S. Luthra, D. Huisingh, S. K. Mangla, B. E. Narkhede, and Y. Liu, "Development of a lean manufacturing framework to enhance its adoption within manufacturing companies in developing economies," Journal of Cleaner Production, 2019.

[2] R. Henao, W. Sarache, and I. Gómez, "Lean manufacturing and sustainable performance: Trends and future challenges," Journal of Cleaner Production, vol. 208, 2019, pp. 99-116.

[3] M. Thürer, Y. H. Pan, T. Qu, H. Luo, C. D. Li, and G. Q. Huang, "Internet of Things (IoT) driven kanban system for reverse logistics: solid waste collection," Journal of Intelligent Manufacturing, 2016.

[4] D. Kolberg, J. Knobloch, and D. Zühlke, "Towards a lean automation interface for workstations," International Journal of Production Research, 55 (10), 2017; pp. 2845-2856.

[5] J. Bhamu and K. S. Sangwan, "Lean manufacturing: literature review and research issues," International Journal of Operations and Production Management, 34 (7), 2014, pp. 876-940.

[6] D. Kolberg and D. Zühlke, "Lean Automation enabled," by Industry 4 Technologies, IFAC 2015, 48 (3), 2015, pp. 1870-1875.

[7] A. Raj, G. Dwivedi, A. Sharma, A. B. Lopes de Sousa Jabbour, and S. Rajak, "Barriers to the adoption of industry 4.0 technologies in the manufacturing sector: An inter-country comparative perspective," International Journal of Production Economics, 2019.

[8] G. Büchi, M. Cugno, and R. Castagnoli, "Smart factory performance and Industry 4.0," Technological Forecasting and Social Change, vol. 150, 2020.

[9] G. Hoellthaler, S. Braunreuther, and G. Reinhart, "Requirements for a methodology for the assessment and selection of technologies of digitalization for lean production systems," Procedia CIRP, vol. 79, 2019.

[10] Stefan Seifermann, Jörg Böllhoff, Carsten Schaede, Michael Kutzen, Joachim Metternich, "Novel method to systematically implement lean production in machining areas," Procedia CIRP, vol. 78, 2018, pp. 61-66.

[11] J. Patalas-Maliszewska and S. Kłos, "The methodology of the S-ERP system employment for small and medium manufacturing companies," IFAC-PapersOnLine, vol. 52, iss. 10, 2019, pp. 85-90.

[12] S. Kłos, "A Model of an ERP-Based Knowledge Management System for Engineer-to-Order Enterprises," In Dregvaite, G., Damasevicius, R. (eds.), Information and Software Technologies, ICIST 2016, Communications in Computer and Information Science, 639, Springer, Berlin, 2016, pp. 42-52.

[13] S. Jituri, B. Fleck, and R. Ahmad, "Lean OR ERP - A Decision Support System to Satisfy Business Objectives," Procedia CIRP, vol. 70, 2018, pp. 422-427.

[14] J. Patalas-Maliszewska and S. Kłos, "The methodology of the S-ERP system employment for small and medium manufacturing companies," IFAC-PapersOnLine, vol. 52, iss. 10, 2019, pp. 85-90.

[15] F. Gleeson, P. Coughlan, L. Goodman, A. Newell, and V. Hargaden, "Improving manufacturing productivity by combining cognitive engineering and lean-six sigma methods," Procedia CIRP, vol. 81, 2019, pp. 641-646. 